\title{
Warfarin doz ayarlanmasında genetik varyasyonların etkisi
}

\author{
Gülbahar DARILMAZ YÜCE${ }^{1}$
}

${ }^{1}$ Dışkapı Yıldırım Beyazıt Eğitim ve Araştırma Hastanesi, Göğüs Hastalıkları Kliniği, Ankara, Türkiye

${ }^{1}$ Clinic of Chest Diseases, Diskapi Yildirim Beyazit Training and Research Hospital, Ankara, Turkey

\section{ÖZET}

\section{Warfarin doz ayarlanmasında genetik varyasyonların etkisi}

Warfarin en yaygın kullanılan oral antikoagülandır. Dar bir terapötik indekse sahiptir, bu nedenle, warfarin alan hastalarda antikoagülan yanıt sık kontrol gerektirir. Yaş, cinsiyet, komorbiditeler, birlikte alınan ilaçların yanı sıra farmakokinetik ve farmakogenetik genlerdeki varyasyonlar da warfarin dozunu etkilemektedir. VKORC1 ve CYP2C9 warfarin metabolizmasından sorumlu iki gendir. Günümüzde warfarin metabolizmasındaki önemleri ve kliniğe yansımaları yeterince bilinmemektedir. Bu genlerdeki polimorfizmler warfarine yanıtta duyarlılı̆a ve aşırı antikoagülasyona hatta hemorajik komplikasyonlara neden olmaktadır. Genetik polimorfizm araştırması özellikle uluslararası normalleştirilmiş oran (INR) düzeyi ayarlanamayan hastalarda faydalı olmaktadır. Farklı ırklarda ve toplumlarda bu iki genin sıklığı da farklıdır. Bu durum warfarine yanıtta çeşitliliğe neden olmaktadır. Günümüzde warfarin dozu ayarlanırken halen genetiğin rolü göz ardı edilmektedir. Bu polimorfizmler için genetik analiz yapmanın hasta takibi ve maliyete sağlayacağı katkılar halen tartışmalıdır. Bu konuyla ilgili Amerika ve Avrupa'da yapılmakta olan çok merkezli çalışmalar devam etmektedir.

Anahtar kelimeler: Genetik varyasyon, warfarin, CYP2C9, VKORC1

\section{SUMMARY}

Effect of genetic variations on adjusting of warfarin dose

Warfarin is the most widely used oral anticoagulant. Since it has a limited therapeutics index, anticoagulant reaction is mostly needed to be controlled in patients taking warfarin. Besides age, gender, medicines taken with comorbidities, the variations in pharmacokinetiCS and pharmacogenetic genes also affect the dose of warfarin. VKORC1 and CYP2C9 are two genes responsible for warfarin metabolism. Today the importance and clinical effects of warfarin in metabolism are not known sufficiently. The polymorphisms in these genes cause sensitivity and over anticoagulant even hemorrhagic complication in warfarin reaction. Genetic polymorphism research is beneficial especially in patients where international normalized ratio (INR) level cannot be adjusted. The frequency of these genes is also different in different races and populations. This condition causes variety in warfarin reaction. Today the role of genetics is still ignored in adjusting warfarin dose. The contributions of doing genetic analysis for polymorphisms to patient follow ups and expenditure are still contradictive. Multicentric studies about this subject are going on in the USA and Europe.

Key words: Genetic variations, warfarin, CYP2C9, VKORC1

\section{Yazışma Adresi (Address for Correspondence)}

\section{Dr. Gülbahar DARILMAZ YÜCE}

Dışkapı Yıldırım Beyazıt Eğitim ve Araştırma Hastanesi, Gögüus Hastalıkları Kliniği, ANKARA - TURKEY

e-mail: yucegulbahar@yahoo.com.tr 


\section{Giriş}

Wisconsin Mezunları Araştırma Vakfı tarafından keşfedilen warfarin, 1950'li yılllarda piyasaya sürüldügünden beri yaygın olarak kullanılan oral antikoagülandır $(1,2)$. Günümüzde gelişmiş dünya nüfusunun $\% 1-2$ 'si bu oral antikoagülanı düzenli olarak almaktadır (1). Derin ven trombozu, pulmoner embolizm, mekanik kapak replasmanı, atriyal fibrilasyon ve inme profilaksisinde kullanılmaktadır (3).

Warfarin kullanan hastalar terapötik doza ulaşabilmek için $10 \mathrm{mg}$ ile $100 \mathrm{mg} / \mathrm{hafta}$ gibi geniş bir doz aralığında ilaç kullanmak zorundadır (4). Dar bir terapötik indekse sahip olan warfarin subterapötik dozda pıhtı oluşumu ve supraterapötik dozda kanama oluşumuna neden olur (1). Bu nedenle, warfarin alan hastaların yakın izlemi gerekir. Bu durum sağlık sistemleri için pahalı bir yatırım, hastalar için de rahatsızlık yaratır. 2006 yılında Amerika Birleşik Devletleri (ABD)'nde acil servise warfarin kullanımına bağlı yan etkiler nedeniyle 36.000 kişi başvurmuştur (5). Hemorajik olay görülme oranı $\% 12^{\prime}$ dir ve bunların $\% 2$ 'si mortal seyreder (6). Warfarin tedavisinin ilk ayındaki kanama riski, ilk yıldan sonraki riske göre 10 kat daha fazladır. Kanamalar sıklıkla gastrointestinal sistem, yumuşak doku ve üriner sistemden olmaktadır (7). Warfarin tedavisi sırasında majör kanama olaylarının insidansı RE-LY (Uzun Süreli Antikoagülasyon Tedavisinin Randomize Değerlendirmesi) çalışmasına göre, hasta başına yılda ortalama \%3.36'dır (8). İleri yaş, kadın cinsiyet, kontrolsüz hasta, yüksek dozda antikoagülan kullanımı, ek hastalıklar ve eş zamanlı ilaçların hemorajik komplikasyonları artırdığı, düşük beden kitle indeksi (BKi) olanlarda daha düşük doz gerektiği bilinmektedir $(3,9)$. Diyet de warfarin metabolizmasını etkilemektedir (10). Ayrıca, karaciğer hastalığı, hipertiroidizm ve kalp yetmezliğinin de ilaca hassasiyeti artırdığı tespit edilmiştir (1). Tedavi etkinliği ve warfarinin güvenli kullanımı protrombin zamanı ve uluslararası normalleştirilmiş oran (INR) ile takip edilir $(3,11)$. Terapötik seviyeleri aşan INR değerleri kanama riskinin artmasına neden olmaktadır. INR değerleri terapötik seviyenin altında ise, tromboembolik olaylarda artış olmaktadır (12). Tedavi başlangıcında herhangi bir hasta için optimal doz belirsiz olduğundan tedaviye genelde ampirik dozda başlanır. Bu dönemde aşırı antikoagülasyon veya hemoraji gelişme riski yüksektir (13).

Son 10 yılda warfarin dozundaki çeşitliliklerin warfarin metabolizması ve aktivitesinden sorumlu genlere ait varyasyonlardan dolayı meydana geldiği ve çeşitliliğin \%40'ından sorumlu olduğuna ilişkin kanıtlar elde edilmiştir (3). Farmakokinetik ve farma- kogenetik genlerdeki varyasyonlar warfarin dozunu etkilemektedir (4).

Warfarin, koagülasyon faktörlerinden 2, 7, 9, 10'un gama-karboksilasyonunu engelleyerek aktivasyonlarını önlemektedir (7). Vitamin K'nın inaktif formu olan Vitamin K epoksit, Vitamin K epoksit redüktaz (VKOR) enzimi ile indirgenmiş Vitamin K'ya [Vitamin K (H2)] dönüştürülür. VitKH2 proton kaynağı sağlayarak, faktör 2, 7, 9, 10'un gama-glutamil karboksilaz enzimi ile gama-glutamil karboksilasyona uğrayıp fonksiyonel olmaları için katalizör görevi görür. Warfarin tarafından VKOR enzimi bloke edilerek Vitamin $K^{\prime}$ ’nı indirgenmiş haline dönüşümü inhibe edilir $(3,7)$ (Şekil 1).

Klinik olarak kullanılan warfarin \%50 R-warfarin ve \%50 S-warfarinin rasemik bir karışımıdır. Sitokrom p450 2C9 S-warfarininin aktif metabolitleri olan 6-hidroksi-S-warfarin ve 7-hidroksi-S-warfarine dönüşümünü katalize eder. R-warfarin metabolizmasından sorumlu olan sitokrom P4501A2, 2C19 ve 3A4Rwarfarininin aktif metabolitleri olan 6-hidroksi-Rwarfarin ve 7-hidroksi-R-warfarine dönüşümünü katalize eder. S-warfarinin metabolik eliminasyonu R-warfarinden üç kat daha hızlıdır. R-warfarinle karşılaştırıldığında S-warfarin VKOR enzim inhibitörü olarak beş kat daha aktiftir $(3,7)$.

Sitokrom P450 (CYP) endojen steroidleri, yabancı kimyasal madde ve ilaçları metabolize eden bir enzim süper ailesidir. Bu ailenin, bir üyesi olan CYP2C9, warfarin metabolizmasında önemlidir (1). Hepatik CYP2C9 warfarinin daha aktif izomeri olan S-warfarinin metabolizmasından sorumludur. CYP2C9'un aktivitesinde azalmaya sebep olan birkaç CYP2C9 polimorfizmi saptanmıştır. Bu azalmış serum aktivitesi warfarin seviyelerinde artmaya neden olur. Bu da terapötik INR'ye ulaşmak için daha düşük dozların yeterli olmasını sağlar, böyle hastalarda, diğer hastalarda normal olan dozlar kanamaya neden olabilir (7). CYP2C9 genindeki polimorfizm dışında warfarin dozunu etkileyen diğer genetik varyasyon Vitamin $\mathrm{K}$ metabolizmasından sorumlu VKORC1 genindeki polimorfizmlerdir. Warfarin doz çeşitliliklerinin yaklaşık olarak \%30'u bu iki polimorfizmden dolayı olmaktadır (4). Aithal ve arkadaşları ilk olarak 1999 yılında CYP2C9 gen varyantlarının warfarin metabolizmasında değişikliklere neden olduğunu bulmuşlardır (15). VKORC1 gen varyantları ise 2004 yılında saptanmıştır (16) (Tablo 1).

CYP2C9 geni 10. kromozomun q23.33 bandında yerleşmiştir. Klinik olarak önemli olan polimorfizmleri 430, 818 ve 1075 pozisyonlarında bulunur. *2 olarak bilinen 430 . pozisyonda sitozin yerine timin 


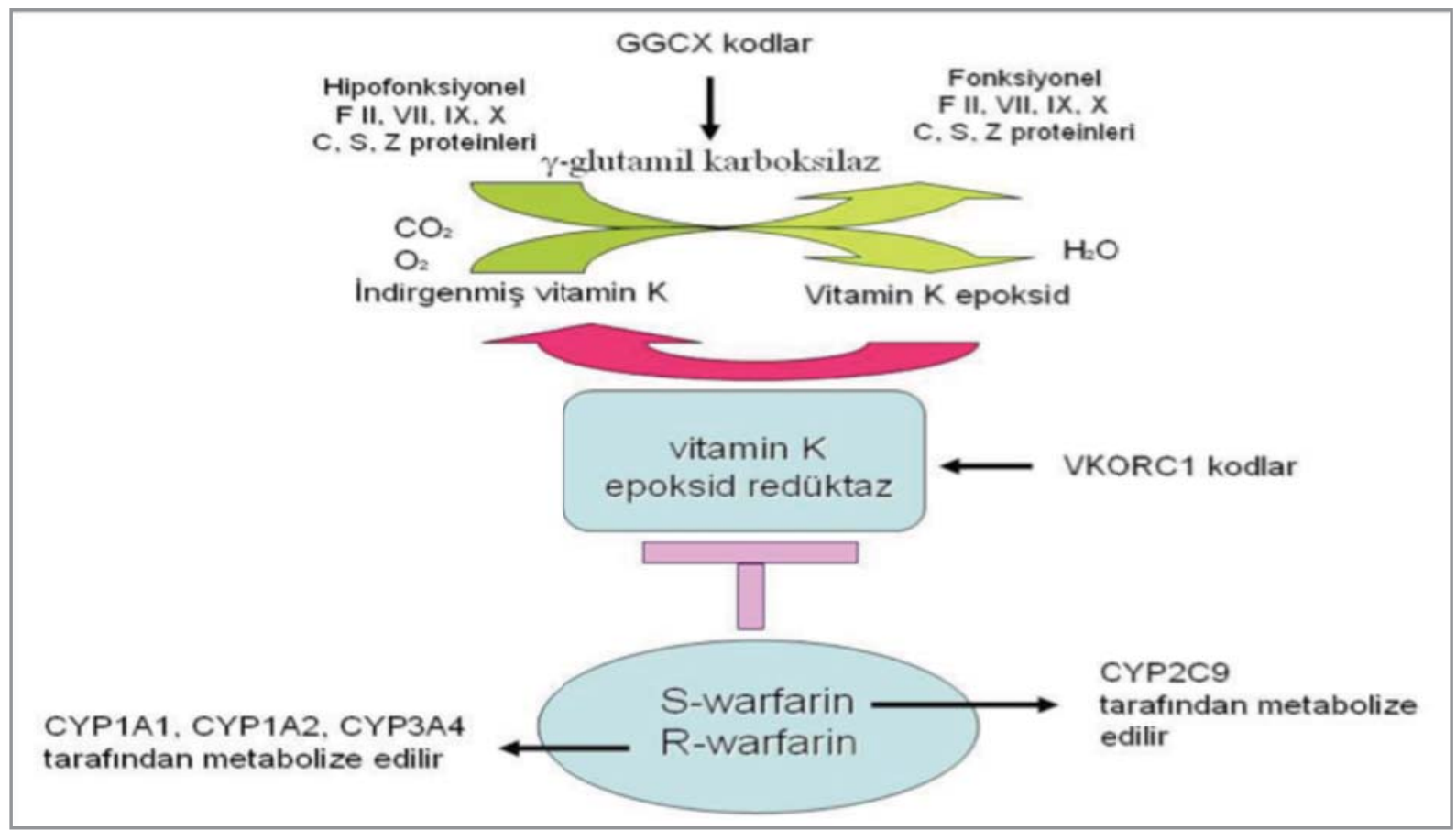

Şekil 1. CYP2C9 ve VKORC1'in Vitamin K metabolizmasındaki önemi (14).

\section{Tablo 1. VKORC1 ve CYP2C9 genotipleri}

\section{VKORC1 genotipleri}

VKORC1-1639 GG ve 1173 CC (wild-tip, olması gereken allel)

VKORC1-1639 GA ve 1173 CT (heterozigot mutant) VKORC1-1639 AA ve 1173 TT (homozigot mutant)

\section{CYP2C9 genotipleri}

CYP2C9 *1/*1 (wild-tip, olması gereken allel)

CYP2C9 $* 1 / 22$ (heterozigot mutant)

CYP2C9 $* 2 / * 2$ (homozigot mutant)

CYP2C9 *1/*3 (heterozigot mutant)

CYP2C9 *3/*3 (homozigot mutant)

gelmesiyle oluşan polimorfizm (430C > T, rs1799853) arjinin yerine sisteinin geldiği bir protein kodlar, *3 olarak bilinen 1075. pozisyonda adenin yerine sitozin gelmesiyle oluşan polimorfizm (1075A > C, rs1057910) izolösin yerine lösinin geldiği bir protein kodlar $(1,7)$. Enzim aktivitesi *2 genotipi için, \%30 azalırken, *3 genotipi için \%80 azalır (1). Hem *2 hem de *3 allelleri S-warfarinin normal allele göre sırasıyla \%12 ve \%5 daha az olan bozulmuş hidroksilasyonuyla sonuçlanır. Bu varyasyonlar warfarinin degradasyonu ve klerensini azaltır. Bundan dolayı terapötik INR elde etmek için düşük bir doz yeterli olur (3). *6 olarak bilinen 818 . pozisyonda adenin delesyonuyla oluşan polimorfizm (818 delA, rs9332131) azalmış enzim aktivitesiyle ilişkilidir. Ayrıca, 19. kromozom q13.12 lokalizasyonunda yerleşmiş olan normal CYP4F2 varyantı (7253232 C > T rs2108622) olan polimorfizm de warfarin metabolizmasını etkiler (7).

VKOR enzimini kodlayan VKORC1 16. kromozom $p$ 11.2'de bulunmaktadır. VKORC1'in transkripsiyonu başlıca karaciğerde, daha az olarak da kalp ve pankreasta yapılmaktadır (7). VKORC1 promoter bölgesindeki polimorfizm 1639. pozisyondaki guanin yerine adenin gelmesiyle meydana gelir (17). 1639 A alleli VKORC1 mRNA'nın azalmış üretimi ve VKOR enziminin azalmış ekspresyonuyla sonuçlanır (18). Bu hastalarda daha düşük warfarin dozlarıyla terapötik INR'ye ulaşılır. Diğer hastalar için normal olan dozlar kanamaya neden olabilir.

Bir meta-analizde özellikle CYP2C9 varyantlarının (*2 ve*3) belirgin olarak hemorajik komplikasyonlarla ilişkili olduğu, CYP2C9 *2 ile karşılaştırıldığında *3'ün warfarinin hemorajik komplikasyonları için daha güçlü bir risk faktörü olduğu belirtilmiştir (2). Çinlilerde yapılan bir çalışmada; VKORC1 polimorfizmlerinin CYP2C9 polimorfizmlerine göre, warfarine erken yanıtı daha çok etkilediği bulunmuştur. VKORC1 mutant genotipleri antikoagülasyonun 
erken dönemlerinde warfarine daha duyarlıdır, bu genotiplerde antikoagülan tedavinin ilk aşaması en zorlu adım olmaktadır (19).

Kafkaslarda yapılan bir çalışmada genotip idame dozundaki değişkenlikten \%19.8 sorumluyken, yaş, vücut yüzey alanı ve erkek cinsiyet sırasıyla \%14.6, $\% 7.5$ ve \%4.7, sorumlu olarak bulunmuştur (20). Kuzey Amerikan toplumunda warfarin doz gereksinimi CYP2C9 *2 için \%19, *3 için \%30, yaşın her 10 yılı için \%8, vücut yüzey alanındaki standart deviasyondaki azalma başına \%13, amiodaron alan (warfarin metabolizmasını güçlü şekilde inhibe eder) hastalarda \%29, simvastatin alan hastalarda \%12, beyazlarda Afrika kökenli Amerikalılarla karşılaştııılı̆̆ında \%11 daha az olarak hesaplanmıştır. Bu faktörler ve cinsiyetin dahil olduğu verilerin analizi sonucunda warfarin idame dozunda varyansın \%39 olduğu açıklanmıştır (21). ABD'de poliklinikte yapılan prospektif bir çalışmada warfarin dozu hakim belirleyicisi olarak yaş, kilo ve cinsiyetin \%12 oranında etkili olmasına karşın genotip \%33 ile dominant faktör olarak belirtilmiştir (22). Bu verilere göre warfarin doz gereksiniminde genetik faktörler; yaş, BKi, cinsiyet ve eşlik eden ilaçlardan daha önemlidir.

Warfarinin allel sıklıklarına göre ortalama günlük idame dozları Hintli bir popülasyonda VKORC11639 GG ve 1173 CC (wild-tip) için $4.72 \mathrm{mg} /$ gün, VKORC 1-1639 GA ve 1173 CT (heterozigot) allelleri için 3.74, VKORC1-1639 AA ve 1173 TT (homozigot) alleleri için 2.07, CYP2C9 $* 1 / * 1$ (wild-tip) için 4.46, CYP2C9 $* 1 / * 2$ (heterozigot) allel için 4.5 , CYP2C9 *2/*2 (homozigot) allel için 2.85 bulunmuştur (3). Türk popülasyonunda VKORC1 -1639 GG (wild-tip) için $5.95 \pm 2.12$, VKORC 1-1639 GA için $3.29 \pm 1.72$ ve VKORC1-1639 AA için $2.49 \pm 1.11$, CYP2C9 *1/*1 (wild-tip) için $4.74 \pm 2.49$, CYP2C9 $* 1 / * 2$ (heterozigot) allel için $3.71 \pm 1.76$, CYP2C9 $* 1 * 3 / * 2 * 3$ allelleri için $3.32 \pm 1.92$ bulunmuştur (11). Kafkaslarda CYP2C9 $* 1 * 1, * 1 * 2, * 1 * 3, * 2 * 2, * 2 * 3$ ve $* 3 * 3$ genotiplerinin ortalama idame dozları sırasıyla $36.5,29.1,23.5,28.0,18.1$ ve $5.5 \mathrm{mg} /$ hafta olarak hesaplanmışıır (20). Bu bulgular günlük warfarin dozunun VKORC1 ve CYP2C9 normal allele sahip hastalarda en yüksek, polimorfizmlerde ise; heterozigotlukta normal allelden daha az, homozigotlukta en az olduğunu göstermektedir.

Farklı ırklarda ve toplumlarda bu iki genin sıklığı da değişmektedir. Son yıllarda warfarin yanıtına farklılıkta etnik toplulukların temel genetik modülatör olduğu belirtilmektedir. Toplam 453 kafkas hastanın
CYP2C9 genotip sıklığının incelendiği çalışmada $* 1 * 1, * 1 * 2, * 1 * 3, * 2 * 2, * 2 * 3$ ve $* 3 * 3$ genotiplerinin toplumda görülme sıklığı sırasıyla $\% 65, \% 19, \% 12$, $\% 1.6, \% 1.8$ ve \%0.4 bulunmuştur (20). Çin popülasyonunda CYP2C9 $* 1 * 1$ genotip sıklığı $\% 95, * 1 * 3 \% 5$ ve $* 3 * 3 \% 0$ olup, $* 2$, *4 ve $* 5$ varyantlarının da olmadığı bildirilmiştir (23). Kafkaslarda VKORC1 allelleri GG, AG, AA \%39, \%47 ve \%14 mevcut iken, Çinli hastalarda ise \%2.7, \%17.6 ve \%79.7 olup, anlamlı olarak farklı olduğu rapor edilmiştir. Çinli hastalarda VKORC1 polimorfizminin daha yaygın ve homozigotluğun fazla gözlenmesinden dolayı benzer derecede antikoagülasyona erişmek için Çinliler kafkaslardan daha düşük doz warfarin gerektirmektedir (17). Hintlilerde CYP2C9 *2 varyant allel nüfusun \%5.4'ünde mevcut iken *3 varyant allel tamamen yok olarak bulunmuştur (3). VKORC1 varyant alleli Hintlilerde nüfusun \%14-19'unda mevcut olup, diğer Asyalılarda olduğundan daha azdır (24). CYP2C9 allel sıklığı Avrupa kökenli Amerikalılarda *2 ve *3 için sırasıyla \%11.24 ve \%5.1, Afrika kökenli Amerikalılarda \%1.1 ve \%1.8 olup, polimorfizm sıklığı Avrupa kökenlilerde Afrika kökenlilere göre fazladır, bu nedenle CYP2C9 polimorfizmi warfarin dozunu öngörmede Avrupa kökenlilerde önemliyken, Afrika kökenlilerde önemsizdir (25). VKORC1 *2 allel sıklığı Afrika kökenli Amerikalılarda \%14, Avrupalılarda \%42'dir (26).

Tüm Asyalılarda VKORC1 polimorfizmi \%90-95 civarında görülmektedir $(27,28)$. Bu nedenle Asyalı hastalar warfarinle antikoagülasyona karşı daha duyarlıdır (29). Asyalılar arasında da, Hintliler; Çinliler, Japonlar ve Malaylardan daha yüksek dozlar gerektirir (3). Çinliler de Kafkaslardan daha düşük doz gerektirmektedir (17). Afrikalı Amerikalılar warfarine daha duyarlı olan Kafkas ve Asyalılara göre daha yüksek dozlara gereksinim duyar (3). Özet olarak, siyah popülasyonda warfarin doz gereksinimi en yüksek, beyaz popülasyonda orta derece, Asyalılarda en düşük olmaktadır (1).

Türk nüfusu, Avrupa ve Asya kökenli farklı etnik gruplardan oluşmaktadır. Türk toplumunda CYP2C9 ve VKORC1 allel sıklığı ve gen polimorfizmlerinin warfarin doz gereksinimleri üzerine etkileri hakkında yayınlanan birkaç çalışma vardır (11,30-32). Toplam 100 stabil Türk hastada yapılan çalışmada warfarin ortalama günlük idame dozu $4.1 \mathrm{mg} /$ gün ve warfarin doz gereksinimi 1.16 ile $9.33 \mathrm{mg} / g u ̈ n$, arasında büyük farklılıklar göstermiştir. Polimorfizmler için varyant allel frekansları VKORC1 A \%40, CYP2C9 *2 $\% 13, * 3 \% 15$ olup, diğer bir Türk popülasyonu çalışmasında aynı genotipler için sıklıklar sırasıyla \%50, 
\%13'e \%10 bulunmuştur (11,32). Türkiye'den yapılan çalışmalarda allel sıklığı sonuçları birbiriyle uyumludur. Ayrıca Türk hastaların sonuçları, Asya ve Afrika kökenli Amerikalılardan farklı olup, en çok Kafkas popülasyonuyla benzemektedir (11). Türk hastalarda VKORC1 ve CYP2C9 polimorfizmlerinin haftalık warfarin dozunda \%40'lık bir azalmaya neden olması dikkat çekicidir (32).

2007 Ağustos ayında, "Food and Drug Administration (FDA)" CYP2C9 ve VKORC1 polimorfizmleri olan belirlenmiş hastalarda warfarin için düşük başlangıç dozları kullanılması gerektiğini belirtmiştir. FDA warfarin tedavisi başlanmadan önce bu genetik varyantlar için test yapılmasını ve ürün etiketlerinde farmakogenetik bilgi verilmesi gerektiğini önermektedir $(19,33)$.

\section{DiĞER GENLERDEKI POLIMORFIZMLER}

CYP4F2'nin K vitamini ve warfarin metabolizmasındaki yolağı tam olarak bilinmemektedir. Warfarin dozu üzerinde \%1-2'lik küçük bir etkisi vardır. TT homozigot allelde, CC homozigot allele göre $1 \mathrm{mg} /$ gün daha fazla warfarin ihtiyacı olmaktadır (34).

Apolipoprotein E (APOE) karaciğerde $\mathrm{K}$ vitamini bakımından zengin lipoproteinlerin reseptöre spesifik alımına aracılık eden, lipidlerin taşınmasında yer alan plazma lipoproteinlerinin önemli bir bileşenidir. APOE genindeki polimorfizmin de kumarinler için doz gereksinimini etkilediği gösterilmiştir. APOE'yi kodlayan üç allel vardır: $\varepsilon 2$, $\varepsilon 3$ ve $\varepsilon 4$. Doz ayarlanmasında farklı allelik varyantların etkileri toplumdaki sıklığına bağııdır. Örneğin; E4 genotipi warfarin doz gereksinimi için küçük bir katkıda bulunmaktadır, bu durumda bu genotipin frekansı Asyalılarda beyazlar ve Afrikalı Amerikalılardan daha düşük olduğu için klinik olarak anlamlı değildir (35).

Gamma-glutamilkarboksilaz (GGCX) vitamin K döngüsünün önemli bir bileşeni olduğu için, bu genin polimorfizmi de önemlidir. Avrupa popülasyonunda, pozisyon 12970 'te tek gen polimorfizmi (rs11676382) warfarin dozunda toplam varyansın \%2'sini açıklarken sırasıyla VKORC1 ve CYP2C9 ise varyansın \%21 ve \%8'ini açıklamaktadır (36).

Trans-hidrodioller için epoksitlerin hidrolizinden sorumlu olan ve vitamin K 2,3-epoksit bağlanma bölgesi gibi davranan mikrozomal epoksit hidrolaz, aynı zamanda, iki polimorfizmi tespit edilmiş olan bir gen tarafından kodlanır (1).

Calumenin bir kalsiyum iyonu bağlanma proteinidir. Aşırı ekspresyonu olduğu zaman, VKOR'a bağlanır ve inhibe eder. $\mathrm{Bu}$, aynı zamanda karboksilaz enzi- mine, vitamin $K^{\prime} n ı n$, indirgenmiş formunun transferini önler. Antikoagülan kullanan bir popülasyonunda, warfarin doz gereksinimi mikrozomal epoksit hidrolaz ve calumenin genlerinin polimorfizminden etkilenmemiştir (1).

Toplam 550.000 polimorfizmin test edildiği retrospektif bir çalışma warfarin doz gereksiniminde en belirgin olarak VKORC1, orta derecede CYP2C9 *2 ve *3 polimorfizmlerinin etkili olduğunu ortaya koymuştur. Bu çalışmada GGCX, çeşitli farklı pıhtılaşma faktörleri, mikrozomal epoksit hidrolaz, diğer CYP2C9 sitokrom P450 izoformları, bazı glutatyonS-transferaz izoformları, APOE ve protein C kodlayan diğer genlerin çok az ya da hiç katkısının olmadığı ortaya çıkmıştır (1).

Ampirik yaklaşımın savunucuları farmakogenetik kılavuzluğunda doz algoritmasındansa daha iyi hasta eğitimi ve daha yakın takip ile dozlama doğruluğunun artırılabileceğini savunmaktadırlar. Toplam 1015 hastanın tedavinin ilk dört haftasında incelendiği bir çalışmada warfarinin genotip tabanlı dozlamasının yararı gösterilememiştir (37).

Dört kıta (Asya, Avrupa, Kuzey Amerika ve Güney Amerika) dokuz ülke, 21 merkez bilim insanlarından oluşan Uluslararası Warfarin Farmakogenetik Konsorsiyumu (IWPC), 4043 hastadan gelen (klinik ve genetik) verilerle warfarin dozunun doğru tahmin edilmesi için bir algoritma geliştirmiştir. Doz tahmininin doğruluğu 1009 hastalık bir doğrulama kohortu ile değerlendirilmiştir. Doğrulama kohortunda hedef INR'ye erişmek için düşük ya da yüksek doz gereken hastalar (haftalık $21 \mathrm{mg}$ ya da daha az, $49 \mathrm{mg}$ ya da daha fazla) büyük oranda doğru tanımlanmıştır. En büyük faydası düşük ve yüksek doz alan hastalarda gözlenmiştir (1).

Farmakogenetiğe dayalı dozlamanın hasta sonuçlarını geliştirip geliştirmeyeceğini değerlendirmek amacryla halen iki büyük, prospektif, çok merkezli ( $A B D$ 'de ve Avrupa'da), randomize, klinik çalışma sürdürülmektedir. Genetik yoluyla optimal antikoagülasyonun aydınlatılması olarak adlandırılan $\mathrm{ABD}$ deneyi (COAG), Ulusal Kalp Akciğer ve Kan Enstitüsü tarafından finanse edilmektedir. On iki klinik alandan farklı etnik köken ve geçmişten olan 1200 hasta değerlendirilecektir. Hastaların yarısı tek başına klinik bilgilere göre randomize olacak ve diğer yarısı IWPC tarafından geliş̧irilen denkleme göre dozlanacaktır. Tüm hastalar altı ay boyunca izlenecektir. Avrupa deneyi Kumarin Tedavisine Farmakogenomik Yaklaşım (EU-PACT), olarak adlandırılmıştır. Yedi ülkeden 13 merkez bu çalışmada yer almaktadır. 
Çalışma Avrupa Komisyonu FP7 programı tarafından desteklenmektedir. Her bir coumarin kolu için 1000 hasta çalışılacaktır. EU-PACT deneyi CYP2C9 ve VKORC1 genotiplemesi için hızlı ve ucuz bir noktabakım testi kullanmaktadır (HyBeacon ${ }^{\circledR}$ technology). Genotip-leme yeni tanılı bir hastada 1 saat içinde kullanılabilir hale getirilmiş̧ir (1).

Sonuç olarak, warfarin dozu ile CYP2C9 ve VKORC1 genleri arasındaki ilişki çok sayıda çalışma ile kanıtlandığı gibi, artık tartışılmazdır. FDA tarafından da bu genlerde varyasyonları olan hastalar için warfarine düşük dozlarda başlanması gerektiği önerilmiştir. Genetiğin hekimleri uyarmadaki yararı ve FDA önerisine rağmen, warfarin doz doğruluğunu düzeltmek için genetik bilginin nasıl kullanılacağı bilinmemektedir. İdeal doz algoritması hedefi aşmadan ya da yetersiz antikoagülasyon olmaksızın kanama ve tromboemboli komplikasyonlarını önlemeli, INR izleme sıklığını ve belirsizliği azaltmalıdır. Genetiğe dayalı dozlama tedaviye başlanmadan önce yapılır ise yararlı olarak önerilmektedir. Günümüzde farmakogenetik tabanlı warfarindoz algoritması henüz rutinde kullanılmamaktadır. ABD ve Avrupa çalışmaların sonuçlarının 3-4 yıl içinde sonuçlanması bekleniyor. Tedaviye ilişkin komplikasyonları azaltıp, maliyet-etkinliği ve pratiklik sağlarsa, gelecekte warfarin başlanmadan önce kullanılabilir.

\section{ÇIKAR ÇATIŞMASI}

Bildirilmemiştir.

\section{KAYNAKLAR}

1. Kamali F, Wynne H. Pharmacogenetics of warfarin. Annu Rev Med 2010;61:63-75.

2. Yang J, Chen Y, Li X, Wei X, Chen X, Zhang L, et al. Influence of CYP2C9 and VKORC1 genotypes on the risk of hemorrhagic complications in warfarin-treated patients: a systematic review and meta-analysis. Int J Cardiol 2013;168(4):4234-43.

3. Natarajan S, Ponde CK, Rajani RM, Jijina F, Gursahani $R$, Dhairyawan PP, et al. Effect of CYP2C9 and VKORC1 genetic variations on warfarin dose requirements in Indian patients. Pharmacol Rep 2013;65(5):1375-82.

4. Daneshjou R, Tatonetti NP, Karczewski KJ, Sagreiya $H$, Bourgeois S, Drozda K, et al. Pathway analysis of genomewide data improves warfarin dose prediction. BMC Genomics 2013;14(3):11.

5. Budnitz DS, Pollock DA, Weidenbach KN, Mendelsohn AB, Schroeder TJ, Annest IL. National surveillance of emergency department visits for outpatient adverse drug events. JAMA 2006;296(15):1858-66.
6. Li T, Lange $L A, L i X$, Susswein L, Bryant B, Malone $R$, et al. Polymorphism in the VKORC1 gene is strongly associated with warfarin dosage requirements in patients receiving anticoagulation. J Med Genet 2006;43(9):740-4.

7. Moyer TP, O'Kane DI, Baudhuin LM, Wiley CL, Fortini A, Fisher $P K$, et al. Warfarin sensitivity genotyping: a review of the literature and summary of patient experience. Mayo Clin Proc 2009;84(12): 1079-94.

8. Connolly SJ, Ezekowitz MD, Yusuf S, Eikelboom J, Oldgren J, Parekh A, et al. Dabigatran versus warfarin in patients with atrial fibrillation. N Engl J Med 2009;361:1139-51.

9. Rubboli A, Becattini C, Verheugt FW. Incidence, clinical impact and risk of bleeding during oral anticoagulation therapy. World / Cardiol 2011;3:351-8.

10. Franco V, Polanczyk CA, Clausell N, Rohde LE. Role of dietary vitamin $K$ intake in chronic oral anticoagulation: prospective evidence from observational and randomized protocols. Am J Med 2004; 116:651-6.

11. Ozer N, Cam N, Tangurek B, Ozer S, Uyarel H, Oz D, et al. The impact of CYP2C9 and VKORC1 genetic polymorphism and patient characteristics upon warfarin dose requirements in an adult Turkish population. Heart Vessels 2010;25(2):155-62.

12. Cannegieter SC, Rosendaal FR, Wintzen AR, Van Der Meer FJ, Vandenbroucke JP, Briet E. Optimal oral anticoagulant therapy in patients with mechanical heart valves. N Engl J Med 1995;333:11-7.

13. Schwarz UI, Ritchie MD, Bradford Y, Li C, Dudek SM, FryeAnderson A, et al. Genetic determinants of response to warfarin during initial anticoagulation. N Engl I Med 2008;358:999-1008.

14. Yin T, Miyata T. Warfarin dose and the pharmacogenomics of CYP2C9 and VKORC1 - rationale and perspectives. Thromb Res 2007;120(1):1-10.

15. Aithal G, Day C, Kesteven P, Daly A. Association of polymorphisms in the cytochrome P450 CYP2C9 with warfarin dose requirement and risk of bleeding complications. Lancet 1999;353:717-9.

16. Rost $S$, Fregin A, Ivaskevicius V, Conzelmann E, Hörtnagel $K$, Pelz HJ, et al. Mutations in VKORC1 cause warfarin resistance and multiple coagulation factor deficiency type 2. Nature 2004; $427: 537-41$.

17. Yuan HY, Chen IJ, Lee MT, Wung JC, Chen YF, Charng MJ, et al. A novel functional VKORC1 promoter polymorphism is associated with inter-individual and inter-ethnic differences in warfarin sensitivity. Hum Mol Genet 2005; 14(13): 1745-51.

18. Wang D, Chen H, Momary KM, Cavallari LH, Johnson JA, Sadée $W$. Regulatory polymorphism in vitamin $K$ epoxide reductase complex subunit 1 (VKORC1) affects gene expression and warfarin dose requirement. Blood 2008;112(4):1013-21. 
19. Ye $C$, Jin $H$, Zhang $R$, Sun $Y$, Wang $Z$, Sun $W$, et al. Variability of warfarin dose response associated with CYP2C9 and VKORC1 gene polymorphisms in Chinese patients. J Int Med Res 2014;42(1):67-76.

20. Hillman MA, Wilke RA, Caldwell MD, Berq RL, Glurich I, Burmester JK. Relative impact of covariates in prescribing warfarinaccording to CYP2C9 genotype. Pharmacogenetics 2004; 14:539-47.

21. Gage BF, Eby $C$, Milligan PE, Banet GA, Duncan $J R$, McLeod HL. Use of pharmacogenetics and clinical factors to predict the maintenance dose of warfarin. Thromb Haemost 2004;91:87-94.

22. Carlquist JF, Horne BD, Muhlestein JB, Lappe DL, Whiting $B M$, Kolek MJ, et al. Genotypes of the cytochrome P450 isoform, CYP2C9 and the vitamin $K$ epoxide reductase complex subunit 1 conjointly determine stable warfarin dose: a prospective study. J Thromb Thrombolysis 2006;22:191-97.

23. Wang TL, Li HL, Tjong WY, Chen QS, Wu GS, Zhu HT, et al. Genetic factors contribute to patient-specific warfarin dose for Han Chinese. Clin Chim Acta 2008;396:76-9.

24. Nahar R, Deb R, Saxena R, Puri RD, Verma IC. Variability in CYP2C9 allele frequency: a pilot study of its predicted impact on warfarin response among healthy South and North Indians. Pharmacol Rep 2013;65:187-94.

25. Limdi NA, Goldstein JA, Blaisdell JA, Beasley TM, Rivers CA, Acton RT. Influence of CYP2C9 genotype on warfarin dose among African-Americans and European-Americans. Pers Med 2007;4:157-169.

26. Geisen C, Watzka M, Sittinger K, Steffens M, Daugela $L$, Seifried $E$, et al. VKORC1 haplotypes and their impact on the interindividual and interethnical variability of oral anticoagulation. Thromb Haemost 2005;94:773-79.

27. Takahashi H, Wilkinson GR, Nutescu EA, Morita T, Ritchie $M D$, Scordo MG, et al. Different contributions of polymorphisms in VKORC1 and CYP2C9 to intra- and inter-population differences in maintenance dose of warfarin in Japanese, Caucasians and African-Americans. Pharmacogenet Genomics 2006;16:101-10.
28. Tham $L S$, Goh BC, Nafziger A, Guo $/ Y$, Wang $L Z$, Soong $R$, et al. A warfarin-dosing model in Asians that uses singlenucleotide polymorphisms in vitamin $\mathrm{K}$ epoxide reductase complex and cytochrome P450 2C9. Clin Pharmacol Ther 2006;80:346-55.

29. Cheng TO. Chinese patients require lower dosage of warfarin. Int / Cardiol 2010;139:1.

30. Aynacioglu AS, Brockmöller J, Bauer S, Sachse C, Guzelbey P, Ongen Z, et al. Frequency of cytochrome P450CYP2C9 variants in Turkish population and functional relevance for phenytoin. Br J Clin Pharmacol 1999;48:409-15.

31. Dericioglu N, Babaoglu MO, Saygi S, Bozkurt A, Yasar U. Warfarin resistance with poor CYP2C9 activity and CYP2C9 *1*2 genotype. Ann Pharmacother 2004;38(5):899.

32. Oner Ozgon G, Langaee TY, Feng H, Buyru N, Ulutin T, Hatemi AC, et al. VKORC1 and CYP2C9 polymorphisms are associated with warfarin dose requirements in Turkish patients. Eur J Clin Pharmacol 2008; 64:889-94.

33. Wu AH. Genotype and phenotype concordance for pharmacogenetic tests through proficiency survey testing. Arch Pathol Lab Med 2013;137(9):1232-6.

34. Caldwell MD, Awad T, Johnson JA, Gage BF, Falkowski M, Gardina $P$, et al. CYP4F2 genetic variant alters required warfarin dose. Blood 2008;111(8):4106-12.

35. Lai S, Sandanaraj E, Jada SR, Kong MC, Lee $L H$, Goh BC, et al. Influence of APOE genotypes and VKORC1 haplotypes on warfarin dose requirements. $\mathrm{Br} / \mathrm{Clin}$ Pharmacol 2008;65:260-64.

36. Reider MJ, Reiner AP, Rettie AE. Gamma-glutamyl carboxylase (GGCX) tag SNPs have limited utility for predicting warfarin maintenance dose. I Thromb Haemost 2007; 5:2227-34

37. Kimmel SE, French B, Kasner SE, Johnson JA, Anderson IL, Gage BF, et al. A pharmacogenetic versus a clinical algorithm for warfarin dosing. Engl J Med 2013;12;369(24):2283-93. 